\title{
The lived experience of fatigue in children and adolescents with cancer: a systematic review
}

\author{
D. Tomlinson ${ }^{1}$ • S. Zupanec ${ }^{2}$ - H. Jones ${ }^{2}$ - C. O'Sullivan ${ }^{1} \cdot$ T. Hesser ${ }^{1} \cdot$ L. Sung ${ }^{1,2}$
}

Received: 13 October 2015 / Accepted: 26 April 2016 /Published online: 5 May 2016

(C) Springer-Verlag Berlin Heidelberg 2016

\begin{abstract}
Purpose Objectives of this systematic review were to summarize how fatigue has been described from the perspective of children and adolescents with cancer, the impact of fatigue on quality of life, and child reported contributing factors and potential alleviators of fatigue.

Methods We conducted electronic searches of Ovid Medline, EMBASE, PsycInfo, Science Citation, Social Science Citation (Web of Science), and CINAHL. We included studies of children and adolescents with cancer in which the experience of fatigue was described by the child/adolescent. The search was restricted to publications in English. Themes were summarized.

Results Eleven studies were represented in 18 publications. Ages of included children ranged from 6 to 19 years. Majority of studies used semi-structured interviews to elicit participant's perceptions of fatigue. Terms used to describe fatigue included the following: tiredness, weary, loss of strength, dizziness, feeling drained, feeling drowsy, lacking motivation, exhaustion, and feeling emotional. Impact of fatigue related to not being able to participate in regular activities; needing to sleep or rest more; and impact on psychosocial
\end{abstract}

Electronic supplementary material The online version of this article (doi:10.1007/s00520-016-3253-8) contains supplementary material, which is available to authorized users.

D. Tomlinson

lillian.sung@sickkids.ca

1 Child Health Evaluative Sciences, The Hospital for Sick Children, Toronto, ON, Canada

2 Division of Haematology/Oncology, The Hospital for Sick Children, Toronto, ON M5G 1X8, Canada health. Perceived alleviators of fatigue included exercise, distraction, rest, eating, and drinking.

Conclusions Fatigue is impactful from the perspective of children and adolescents. Future research should focus on prospective exploration of the impact of fatigue on pediatric cancer patients and identifying approaches to reduce fatigue.

Keywords Child perspective $\cdot$ Fatigue $\cdot$ Lived-experience . Tiredness $\cdot$ Cancer

\section{Introduction}

Fatigue has been increasingly recognized as an important symptom in children and adolescents with cancer [1-3]. It affects children and adolescents with cancer at all stages of the disease trajectory from diagnosis to survivorship and the end-of-life period [4-15]. Fatigue has physical, mental, and emotional components and may be characterized by a lack of energy, decreased physical ability, and feelings of tiredness. [16-18] Fatigue is a subjective, multidimensional construct [3] that may occur acutely, episodically, or chronically [3, $17,19]$ with multifactorial etiology $[3,20]$.

The literature of fatigue in children and adolescents with cancer has led to the development of a conceptual framework in an attempt to better understand this complex phenomenon [3, 17, 20-24]. Research into the measurement of incidence and severity of fatigue in children and adolescents with cancer is increasing with some early evaluation of interventions to reduce fatigue [25-28]. However, despite these efforts, there remains a lack of understanding as to how children and adolescents with cancer describe fatigue and the impact of fatigue from the child's perspective. Their perspective is important as the meaning of fatigue is likely to differ between child selfreport and proxy report from healthcare professionals and 
parents $[16,29]$. Further, little is known about children and adolescent perceptions of the factors that contribute to or alleviate fatigue. This knowledge is important as it may help to prioritize screening and treatment of fatigue and may inform future research related to approaches to prevent and treat fatigue in this population.

Several meta-analyses have been performed that investigate quantifiable fatigue in children with cancer [28, 30, 31]. However, the qualitative "lived-experience" of fatigue is under reported. With continued importance associated with fatigue in children with cancer, but limited progress in understanding its affects, we aimed to report on the child's experience of fatigue, to report on the actual experience of how fatigue feels for these children. Therefore, the objectives of this systematic review were to summarize how fatigue has been described from the perspective of children and adolescents with cancer, the impact of fatigue on quality of life, and child/adolescent reported contributing factors and potential alleviators of fatigue.

\section{Methods}

Our systematic review was conducted following the PRISMA guidelines [32].

\section{Search strategy}

We performed electronic searches of the following databases: Ovid Medline (1946 to 20 July 2015), EMBASE (1947 to 20 July 2015), PsycInfo (1867 to 24 July 2015), Science Citation (Web of Science) 1900-2015, Social Science Citation (Web of Science) 1956-2015, and CINAHL (1990 to 20 July 2015). The search strategy used a combination of medical subject headings and text words to identify studies of fatigue in children with cancer. Electronic supplementary material 1 illustrates the complete search strategy. There was no restriction by trial type, but the search was restricted to publications in English.

\section{Strategy for selection of publications for review}

We defined inclusion and exclusion criteria a priori. We included studies in which children and/or adolescents with cancer self-reported on the qualitative experience of fatigue. A study did not have to have a main focus, or primary outcome, of fatigue measurement. Cancer symptom studies, including quantitative studies, were screened for the inclusion of any descriptors of fatigue, even if this was not a primary aim of the published study. Quantitative studies and mixed method studies were included in the review in order to screen for descriptors and reported quotes of fatigue. Quantitative studies may include quotes or comments from participants regarding their fatigue, that we did not want miss, given the paucity of literature on this subject. Exclusion criteria were as follows: (1) Symptom of fatigue not discussed qualitatively; (2) only quantitative data reported; (3) participants over 19 years of age; (4) child's fatigue only reported from parent/care giver or health care professional perspective; and (5) Publication not in English. We chose to exclude those studies not published in English due to the difficulty of translation, particularly when we wanted to report on descriptors and subjective opinions that may not be accurate when translated literally.

Two authors (DT, COS) independently reviewed the titles and abstracts of the studies identified by the search strategy. All potentially eligible studies were retrieved in full. The same authors independently reviewed the full text articles for eligibility. Consensus was reached on all studies included, with an inter-rater reliability of kappa $=1.00$.

\section{Data abstraction}

Data were abstracted from included publications by two reviewers (DT, COS) using standardized data extraction forms. Data abstraction was performed by two reviewers independently. First author, year of publication, purpose of study, study design, and child age were abstracted. Information reported directly from the child related to fatigue descriptors, impact of fatigue on quality of life, perceived contributors, and potential alleviators were also extracted. Quotations were included where relevant.

\section{Analysis}

Data analysis involved coding of fatigue descriptors into themes that related to broader, overarching concepts using thematic analysis [33]. A theme was captured from children's descriptors, if the data or quotes contained something important in relation to the lived experience of fatigue. Ideally, the theme may be apparent in several instances across the data, but this is not necessary to make a crucial point [33]. The two authors followed the phases of thematic analysis according to Braun and Clarke (2006), namely: (1) familiarization with the data (reading and re-reading), (2) generating initial codes, (3) searching for themes, (4) reviewing themes, (5) defining and naming themes, (6) producing the results [33].

We aimed to provide a rich description of the entire data set, due to the subject of the lived-experience of fatigue being under-researched. To this end, we chose to use an inductive thematic approach, as there was no pre-existing code, or preconception. Our analytic process then involved a semantic level, that progressed from description, with data organized to show patterns in semantic content, and then summarized to interpretation, where we attempted to theorize their significance and implications [33]. 


\section{Results}

Figure 1 illustrates the flow diagram of trial identification and selection. [32] Of the 3,191 unique references identified by the search strategy, 86 were retrieved in full and assessed for eligibility. Of the retrieved full text publications, 68 were excluded, leaving a total of 18 publications which were included in this systematic review [10, 16, 17, 24, 34-46].

Table 1 illustrates the characteristics of the included publications. Eighteen publications resulted from 11 studies that have been reported over the last 15 years. There were 4 studies which reported results from the same cohort in multiple publications. In order to not overweight the same study, we chose to include each cohort only once in our review. All children and adolescents in the included studies were on active treatment during participation. The majority of the 11 studies $(n=7)$ used semi-structured interviews to elicit the perspective of fatigue from children and/or adolescents with cancer $[10,34,35,37,43-45]$. These interviews varied in length from 5 to $10 \mathrm{~min}$ to $1 \mathrm{~h}$. One of these 7 studies supplemented the interviews with diaries. [44] One study solely used focus groups, [46] and one used diaries only [36]. One study used focus groups with the adolescent subsample participating in semi-structured interviews [18] and one study used questionnaire interview sheets [40].

Three studies focused only on adolescents greater than 12 years of age while 8 studies included children and adolescents less than 12 years $[35,36,44]$. Only one study that included children and adolescents reported results from the children and adolescent groups separately. [16-18, 24, 41] The youngest child was 6 years of age and only nine 7 year olds were included across the studies. Six studies focused solely on fatigue $[18,34,36,40,44,46]$ while 5 studies reported on the spectrum of symptoms [10, 35, 37, 43, 45] with some containing minimal information about fatigue.

Table 1 summarizes descriptors of fatigue from the perspective of children and adolescents with cancer. The majority of direct quotes reported in all studies were cited by adolescents. However, differences between the small number of children's descriptors and those of adolescents were negligible. Where identified, the verbiage used by adolescents was more mature, but the themes were very similar as those for children. The terms used to describe fatigue included the following: tiredness, weary, loss of strength, dizziness, feeling drained, feeling drowsy, lacking motivation, exhaustion, and feeling emotional. During our review, we were aware that many of the quotes reported were concerned with the effect that tiredness or fatigue had on the children's or adolescents' lives, which we considered as impactful on the child's or adolescent's quality of life. Therefore, we illustrated this impact of fatigue on quality of life from the child or adolescent perspective in Table 1. Thematic analysis, of the direct quotes, resulted in the identification of themes related to: can't do the things they
Fig. 1 Flow diagram of publication identification and selection

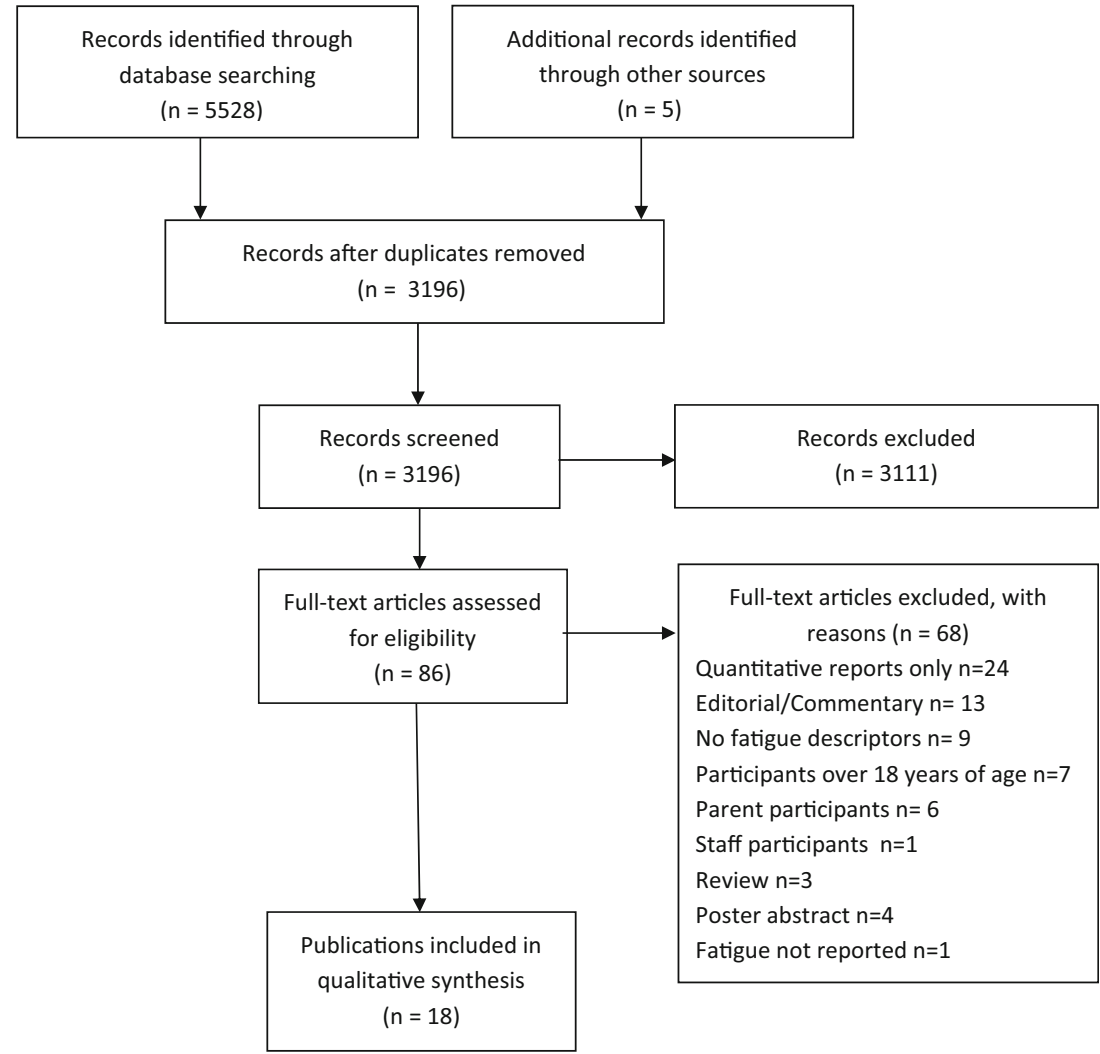




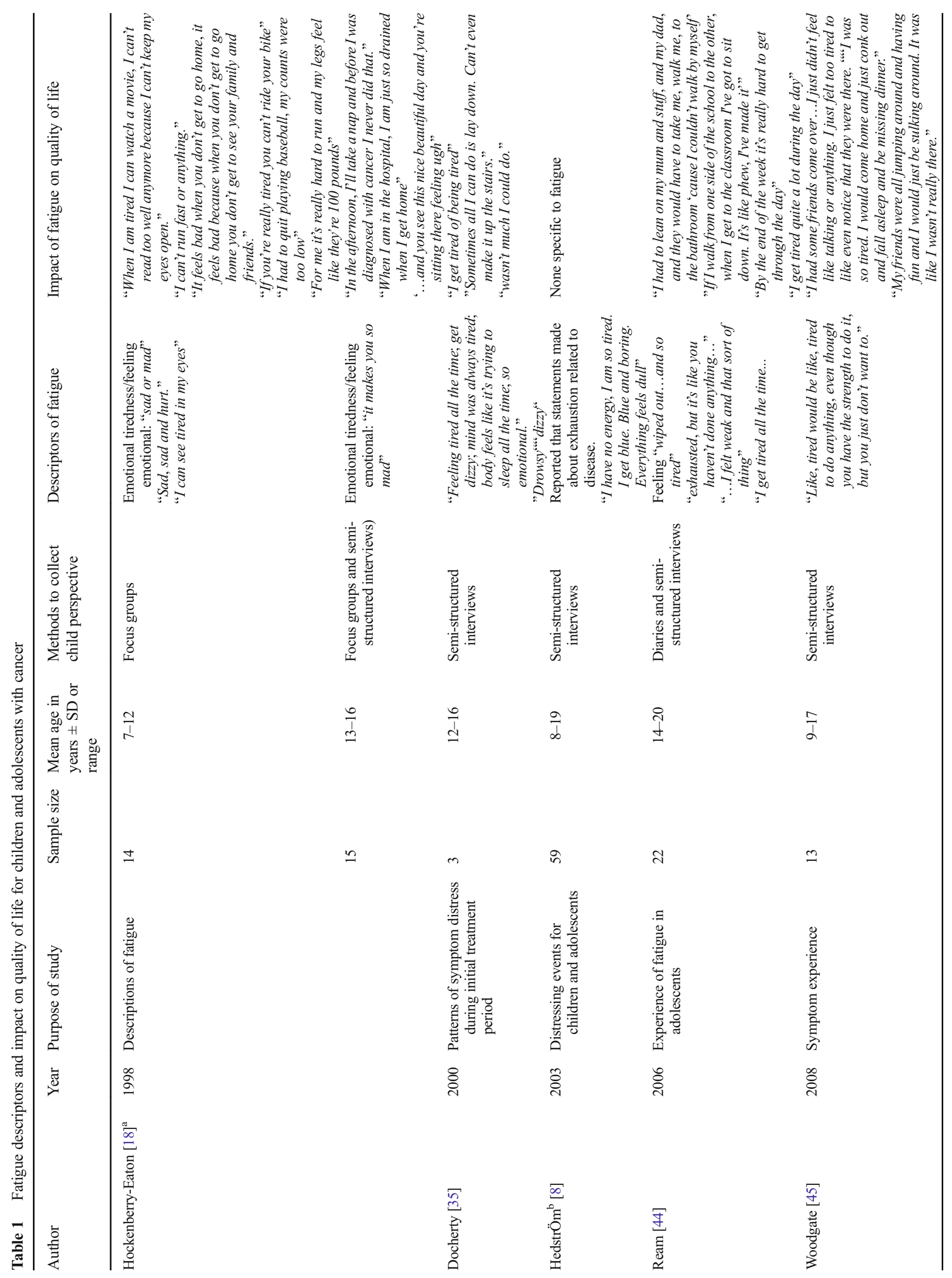




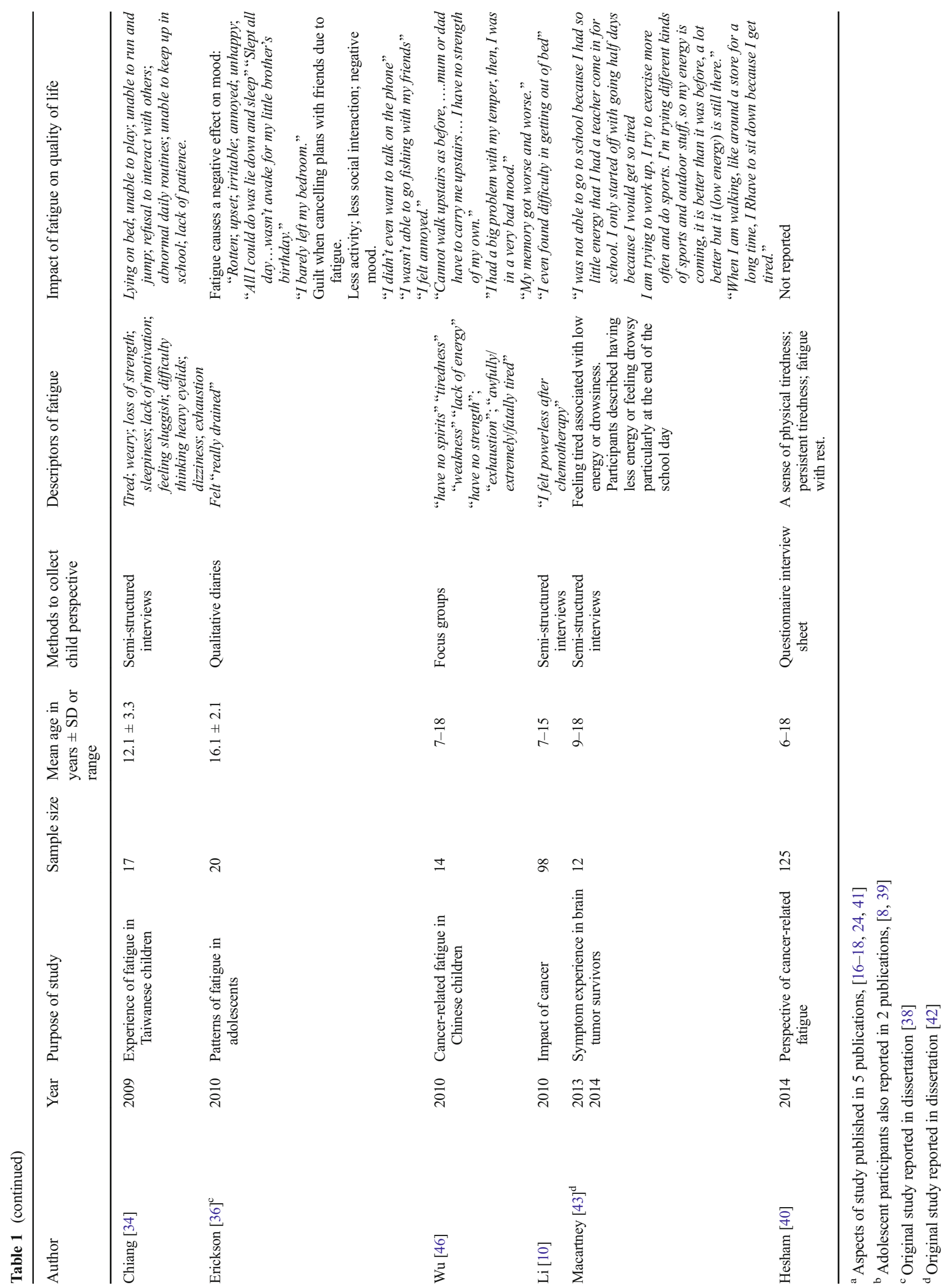


like, inability to participate in regular activities, needing to sleep or rest more, and impact on psychosocial health such as sadness, guilt and annoyance (Table 2).

Table 3 illustrates contributing and alleviating factors from the perspective of children and adolescents; these were reported in 4 studies [18, 36, 43, 46]. Contributing factors included the hospital environment and an assumed side-effect of diagnosis or treatment. Potential alleviating factors as perceived by children and adolescents included rest, exercise, distraction, eating, and drinking. Naps and rest were the most commonly cited factors, followed by increased physical activity.

Table 2 Themes emerging from thematic analysis from included studies $(n=11)$ and corresponding descriptor quotes

Themes Quoted descriptors

Cannot do the things they like

Inability to participate in regular activities
"When I am tired I can watch a movie, I can't read too well anymore because I can't keep my eyes open."

"I can't run fast or anything."

"If you're really tired you can't ride your bike"

"I had to quit playing baseball, my counts were too low"

"For me it's really hard to run and my legs feel like they're 100 pounds"

"I had some friends come over...I just didn't feel like talking or anything. I just felt too tired to like even notice that they were there. "

"My friends were all jumping around and having fun and I would just be sulking around. It was like I wasn't really there."

"I didn't even want to talk on the phone"

"I wasn't able to go fishing with my friends"

"In the afternoon, I'll take a nap and before I was diagnosed with cancer I never did that."

"When I am in the hospital, I am just so drained when I get home"

"... and you see this nice beautiful day and you're sitting there feeling ugh"

"It feels bad when you don't get to go home, it feels bad because when you don't get to go home you don't get to see your family and friends."

"I had to lean on my mum and stuff, and my dad, and they would have to take me, walk me, to the bathroom 'cause I couldn't walk by myself;

"If I walk from one side of the school to the other, when I get to the classroom I've got to sit down. It's like phew, I' ve made it"

"By the end of the week it's really hard to get through the day"

"I get tired quite a lot during the day"

"I was so tired. I would come home and just conk out and fall asleep and be missing dinner."

"I even found difficulty in getting out of bed"

"I was not able to go to school because I had so little energy that I had a teacher come in for school. I only started off with going half days because I would get so tired

I am trying to work up, I try to exercise more often and do sports. I'm trying different kinds of sports and outdoor stuff, so my energy is coming, it is better than it was before, a lot better but it (low energy) is still there."

"When I am walking, like around a store for a long time, I have to sit down because I get tired."

"Drowsy"

"Feeling tired all the time; get dizzy; mind was always tired; body feels like it's trying to sleep all the time"

"I get tired of being tired"

"Sometimes all I can do is lay down. Can't even make it up the stairs."

"wasn't much I could do."

"wiped out... and so tired"

"exhausted, but it's like you haven't done anything..."

"...I felt weak and that sort of thing"

"I get tired all the time...

"really drained"

"All I could do was lie down and sleep"

"Slept all day...wasn't awake for my little brother's birthday."

"I barely left my bedroom."

"tiredness" "weakness" "lack of energy"

"have no strength"; "exhaustion"; "awfully/extremely/fatally tired"

Impact on psychosocial health such as sadness, "sad or mad" guilt and annoyance
"Sad, sad and hurt."

"I can see tired in my eyes"

"it makes you so mad"

"So emotional"

"I get blue. Blue and boring. Everything feels dull"

"Rotten; upset; irritable; annoyed; unhappy"

"I had a big problem with my temper, then, I was in a very bad mood."

"My memory got worse and worse."

"I felt powerless after chemotherapy" 
Table 3 Contributing and alleviating factors of fatigue in children and adolescents with cancer

\begin{tabular}{|c|c|c|}
\hline Study & Contributing factors & Alleviating factors \\
\hline $\begin{array}{l}\text { Hockenberry-Eaton et al. } \\
\text { (1998) [18] }\end{array}$ & $\begin{array}{l}\text { Treatment; being active; pain; sleep pattern } \\
\text { changes; low counts; hospital environment }\end{array}$ & $\begin{array}{l}\text { "I usually take two naps every day and that makes me } \\
\text { feel better" } \\
\text { "Having someone come visit you" } \\
\text { "Reading a book" } \\
\text { "Listening to music" } \\
\text { A good night's sleep. } \\
\text { Being involved in physical therapy. } \\
\text { Symptom relief. } \\
\text { Leaving the hospital setting. }\end{array}$ \\
\hline $\begin{array}{r}\text { Erickson et al. } \\
\text { (2010) [36] }\end{array}$ & $\begin{array}{l}\text { Nausea; pain; sleep disturbances; hospital } \\
\text { environment; resuming usual activities } \\
\text { or lifestyle; treatment-related symptoms } \\
\text { e.g. anemia, increased intravenous fluids }\end{array}$ & $\begin{array}{l}\text { "After I had some lunch, I felt better.", "One thing that } \\
\text { boosted my energy was eating and drinking." } \\
\text { "I took a nap this afternoon and felt a little better afterwards.", } \\
\text { "I guess I needed a power nap." "A nap helped a little." } \\
\text { "The transfusion made me feel slightly better." } \\
\text { "I went swimming and that woke me up big time." } \\
\text { "After basketball, my energy level went up." } \\
\text { "Feeling happy gave me more energy." } \\
\text { "My friend came over and that made me feel better." "Talking } \\
\text { to my friends made me feel better." "My friends made me feel } \\
\text { better and gave me more energy." }\end{array}$ \\
\hline Wu et al. (2010) [46] & Diagnosis of cancer; noise in hospital environment & $\begin{array}{l}\text { "Taking a good sleep." } \\
\text { "Having a rest." } \\
\text { "Avoiding being interrupted by others." } \\
\text { "Exercise." } \\
\text { "Chatting with others." }\end{array}$ \\
\hline Macartney (2014) [43] & Diagnosis of cancer & "I just take breaks." \\
\hline
\end{tabular}

Interestingly, in the study by $\mathrm{Wu}$ et al. (2010) two quotes were reported by adolescents that alluded to an acceptance of fatigue as a symptom:

"Tiredness is normal....for sick patients, it is normal."

"Generally I did not report tiredness....I would like to take this on myself. I think I can handle it" [46]

\section{Discussion}

In this systematic review, we identified 11 studies that included descriptions of fatigue from the child perspective. All 11 studies have been published in peer-reviewed journals; however, evaluation of the qualitative design in each of the included studies was not reported to have followed a standard guideline such as COREQ. [47] Despite this, the content in each of the studies was of high standard across the 3 domains of criteria for reporting qualitative studies, namely:
(1) research team and reflexivity, (2) study design, and (3) analysis and findings.

We found that very little is known about self-reported fatigue in children younger than 7 years of age. However, the limited data suggest that fatigue has an important impact on child/adolescents' quality of life and that children and adolescents are able to report factors that contribute to fatigue and potentially reduce it.

Fatigue has been reported as one of the most prevalent symptoms experienced by children and adolescents with cancer [41, 48]. Nonetheless, others have suggested that fatigue in children and adolescents is under-recognized and under-reported [34]. Reasons for this discrepancy may include a poor understanding of how fatigue is experienced and the impact of fatigue in pediatric cancer. Children and adolescents themselves may not report fatigue as they may assume that it is an inevitable consequence of cancer treatments, and it is a symptom that must be endured with few treatment options [46]. Similarly, it is possible that parents and healthcare providers also believe that fatigue is an expected toxicity and do not emphasize approaches to reduce it. 
We found that from a qualitative perspective, fatigue does appear to impact on child quality of life, particularly with respect to the ability to participate in regular activities. However, we were unable to quantify the magnitude of this impact for children or adolescents.

We also found that young children could verbalize factors that contribute to fatigue as well as factors that potentially may alleviate it. This information is important for two reasons. First, this type of data may provide new hypotheses about interventions which could be effective and could be formally studied. Second, it highlights the need for clinical practice guidelines focused on parents and children about approaches to prevent and treat fatigue.

With only nine 7-year olds being included in these studies, there is limited information about self-report fatigue in younger children. Although eliciting self-report symptoms in young children is challenging, self-reported pain scales and focus groups have been used with children as young as 4 years of age $[49,50]$. However, proxy report by parent or health care provider is still the best measures we have for the very young child (less than 4 years of age). This age group presents a great challenge in characterizing the fatigue experience, while being at an important age to intervene with fatigue alleviators, given the complicated and rapid course of developmental skills, and early learning foundations during this time. Future research should focus on better understanding of fatigue in children and adolescents and, in particular, in younger children.

The strengths of our report are the systematic nature of the identification of studies and that a review of the child's perception of cancer-related fatigue has not previously been published. However, a limitation of this study is the restriction to English language publications. It is possible that additional descriptions of fatigue are present in other languages, and it is also possible that the experience of fatigue differs by culture.

\section{Conclusion}

There is a lack of descriptive data regarding fatigue in young children. More importantly, we know little about the impact of fatigue from the perspective of children. This information is important because severe symptoms, if not bothersome and without morbidity, merit less attention. Consequently, less severe symptoms that are highly bothersome require prioritization. Future research should focus on more detailed prospective exploration of the child's lived experience of fatigue, including description from children younger than 7 years of age. Focus on knowledge of interventions to prevent or treat fatigue could also be examined. A greater understanding of fatigue experienced by children with cancer will assist in improving care and subsequent improvement in health-related quality of life.
Acknowledgments We would like to thank Tamsin Adams-Webber, Library and Archives Manager, Hospital for Sick Children, Toronto, for her invaluable assistance with the literature search strategy.

\section{Compliance with ethical standards}

Conflict of interest The authors declared that they have no conflicts of interest.

Funding The author(s) received no financial support for the research, authorship, and/or publication of this article.

\section{References}

1. Eddy L, Cruz M (2007) The relationship between fatigue and quality of life in children with chronic health problems: a systematic review. J Spec Pediatr Nurs 12(2):105-114

2. Linder LA (2008) Developmental diversity in symptom research involving children and adolescents with cancer. J Pediatr Nurs 23(4):296-309. doi:10.1016/j.pedn.2007.10.003

3. Edwards JL, Gibson F, Richardson A, Sepion B, Ream E (2003) Fatigue in adolescents with and following a cancer diagnosis: developing an evidence base for practice. Eur J Cancer 39(18):26712680. doi:10.1016/j.ejca.2003.09.007

4. Hedstrom M, Ljungman G, von Essen L (2005) Perceptions of distress among adolescents recently diagnosed with cancer. J Pediatr Hematol Oncol 27(1):15-22

5. Berg C, Neufeld P, Harvey J, Downes A, Hayashi RJ (2009) Late effects of childhood cancer, participation, and quality of life of adolescents. OTJR: Occupation, Participation +ACY Health 29(3):116-124

6. Enskar K, von Essen L (2007) Prevalence of aspects of distress, coping, support and care among adolescents and young adults undergoing and being off cancer treatment. Eur J Oncol Nurs 11(5): 400-408. doi:10.1016/j.ejon.2007.01.003

7. Enskar K, von Essen L (2008) Physical problems and psychosocial function in children with cancer. Paediatr Nurs 20(3):37-41

8. Hedstrom M, Haglund K, Skolin I, von Essen L (2003) Distressing events for children and adolescents with cancer: child, parent, and nurse perceptions. J Pediatr Oncol Nurs 20(3):120-132

9. Jalmsell L, Kreicbergs U, Onelov E, Steineck G, Henter J-I (2006) Symptoms affecting children with malignancies during the last month of life: a nationwide follow-up. Pediatrics 117(4):1314 1320

10. Li HCW, Chung OKJ, Chiu SY (2010) The impact of cancer on children's physical, emotional, and psychosocial well-being. Cancer Nurs 33(1):47-54. doi:10.1097/NCC.0b013e3181aaf0fa

11. Linder LA (2005) Measuring physical symptoms in children and adolescents with cancer. Cancer Nurs 28(1):16-26. doi:10.1097/ 00002820-200501000-00003

12. Pritchard M, Burghen E, Srivastava DK, Okuma J, Anderson L, Powell B, Furman WL, Hinds PS (2008) Cancer-related symptoms most concerning to parents during the last week and last day of their child's life. Pediatrics 121(5):e1301-e1309. doi:10.1542/peds. 2007-2681

13. Wolfe J, Grier HE, Klar N, Levin SB, Ellenbogen JM, SalemSchatz S, Emanuel EJ, Weeks JC (2000) Symptoms and suffering at the end of life in children with cancer. N Engl J Med 342(5):326333 
14. Griffith KC, Hart LK (2000) Characteristics of adolescent cancer survivors who pursue postsecondary education. Cancer Nurs 23(6): 468-476 469

15. Hicks J, Bartholomew J, Ward-Smith P, Hutto CJ (2003) Quality of life among childhood leukemia patients. J Pediatr Oncol Nurs 20(4):192-200

16. Hinds PS, Hockenberry-Eaton M, Gilger E, Kline N, Burleson C, Bottomley S, Quargnenti A (1999) Comparing patient, parent, and staff descriptions of fatigue in pediatric oncology patients. Cancer Nurs 22(4):277-289

17. Hockenberry-Eaton M, Hinds P, O'Neill JB, Alcoser P, Bottomley S, Kline NE, Euell K, Howard V, Gattuso J (1999) Developing a conceptual model for fatigue in children including commentary by Eiser C and Enskar K. Eur J Oncol Nurs 3(1):5-13

18. Hockenberry-Eaton M, Hinds PS, Alcoser P, O'Neill JB, Euell K, Howard V, Gattuso J, Taylor J (1998) Fatigue in children and adolescents with cancer. J Pediatr Oncol Nurs 15(3):172-182

19. Gibson F, Garnett M, Richardson A, Edwards J, Sepion B (2005) Heavy to carry: a survey of parents' and healthcare professionals' perceptions of cancer-related fatigue in children and young people. Cancer Nurs 28(1):27-35

20. Hockenberry-Eaton M, Hinds PS (2000) Fatigue in children and adolescents with cancer: evolution of a program of study. Semin Oncol Nurs 16(4):261-272 discussion 272-268

21. Gibson F, Edwards J, Sepion B, Richardson A (2006) Cancerrelated fatigue in children and young people: survey of healthcare professionals' knowledge and attitudes. Eur J Oncol Nurs 10(4): 311-316

22. Gibson F, Mulhall AB, Richardson A, Edwards JL, Ream E, Sepion BJ (2005) A phenomenologic study of fatigue in adolescents receiving treatment for cancer. Oncol Nurs Forum 32(3):651-660

23. Hinds PS, Hockenberry-Eaton M, Quargnenti A, May M, Burleson C, Gilger E, Randall E, Brace-Oneill J (1999) Fatigue in 7- to 12year-old patients with cancer from the staff perspective: an exploratory study. Oncol Nurs Forum 26(1):37-45

24. Hinds PS, Hockenberry-Eaton M (2001) Developing a research program on fatigue in children and adolescents diagnosed with cancer. J Pediatr Oncol Nurs 18(2):3-12

25. Diorio C, Schechter T, Lee M, O'Sullivan C, Hesser T, Tomlinson D, Piscione J, Armstrong C, Tomlinson G, Sung L (2015) A pilot study to evaluate the feasibility of individualized yoga for inpatient children receiving intensive chemotherapy. BMC Complement Altern Med 15(1):2. doi:10.1186/s12906-12015-10529-12903

26. Tomlinson D, Hinds PS, Ethier MC, Ness KK, Zupanec S, Sung L (2013) Psychometric properties of instruments used to measure fatigue in children and adolescents with cancer: a systematic review. J Pain Symptom Manag 45(1):83-91. doi:10.1016/j.jpainsymman. 2012.1002.1010

27. Erickson JM, MacPherson CF, Ameringer S, Baggott C, Linder L, Stegenga K (2013) Symptoms and symptom clusters in adolescents receiving cancer treatment: a review of the literature. Int J Nurs Stud 50(6):847-869 823p. doi:10.1016/j.ijnurstu.2012.10.011

28. Tomlinson D, Diorio C, Beyene J, Sung L (2014) Effect of exercise on cancer-related fatigue: a meta-analysis. Am J Phys Med Rehabil/ Assoc Acad Phys 93(8):675-686

29. White AM (2001) Clinical applications of research on fatigue in children with cancer. J Pediatr Oncol Nurs 18(2 Suppl 1):17-20

30. Chang CW, Mu PF, Jou ST, Wong TT, Chen YC (2013) Systematic review and meta-analysis of nonpharmacological interventions for fatigue in children and adolescents with cancer. Worldviews Evid Based Nurs/Sigma Theta Tau Int Honor Soc Nurs 10(4):208-217. doi:10.1111/wvn.12007

31. Tsai HF, Chen YR, Chung MH, Liao YM, Chi MJ, Chang CC, Chou KR (2014) Effectiveness of music intervention in ameliorating cancer patients' anxiety, depression, pain, and fatigue: a meta- analysis. Cancer Nurs 37(6):E35-E50. doi:10.1097/ncc. 0000000000000116

32. Moher D, Liberati A, Tetzlaff J, Altman DG (2009) Preferred reporting items for systematic reviews and meta-analyses: the PRISMA statement. Ann Intern Med 151(4):264-269 W264

33. Braun V, Clarke V (2006) Using thematic analysis in psychology. Qual Res Psychol 3(2):77-101. doi:10.1191/1478088706qp063oa

34. Chiang YC, Yeh CH, Wang KW, Yang CP (2009) The experience of cancer-related fatigue in Taiwanese children. Eur J Cancer Care 18(1):43-49. doi:10.1111/j.1365-2354.2007.00884.x

35. Docherty SL (2000) Patterns of symptom distress during the initial treatment period in three children with cancer. Diss Abs Int Sec B Sci Eng 60(9-B):4519

36. Erickson JM, Beck SL, Christian B, Dudley WN, Hollen P, Albritton K, Sennett MM, Dillon R, Godder K (2010) Patterns of fatigue in adolescents receiving chemotherapy. Oncol Nurs Forum 37(4):444-455

37. Hedström M, Haglund K, Skolin I, von Essen L (2003) Distressing events for children and adolescents with cancer: child, parent, and nurse perceptions. J Pediatr Oncol Nurs 20(3):120-132

38. Erickson JM (2008) Fatigue and sleep disturbances in adolescents receiving chemotherapy. University of Utah, Salt Lake City

39. Hedstrom M, Skolin I, von Essen L (2004) Distressing and positive experiences and important aspects of care for adolescents treated for cancer. Adolescent and nurse perceptions. Eur J Oncol Nurs 8(1):617. doi:10.1016/j.ejon.2003.09.001

40. Hesham M, El-Dakhakhny AM, Bassam SEA, Fattah NRA, Abd Elaziz RAE (2014) Perspective of children with cancer about cancer related fatigue: a single center experience. Haematologica 99: 219-219

41. Hockenberry-Eaton M, Hinds PS (2000) Fatigue in children and adolescents with cancer: evolution of a program of study including commentary by Mock V and Barr RD. Semin Oncol Nurs 16(4): 261-276

42. Macartney G (2013) Symptom experience and quality of life in children who have survived a brain tumour. Queen's University (Canada),

43. Macartney G, Stacey D, Harrison MB, VanDenKerkhof E (2014) Symptoms, coping, and quality of life in pediatric brain tumor survivors: a qualitative study. Oncol Nurs Forum 41(4):390-398. doi 10.1188/14.ONF.390-398

44. Ream E, Gibson F, Edwards J, Seption B, Mulhall A, Richardson A (2006) Experience of fatigue in adolescents living with cancer. Cancer Nurs 29(4):317-326

45. Woodgate RL (2008) Feeling states - a new approach to understanding how children and adolescents with cancer experience symptoms. Cancer Nurs 31(3):229-238

46. Wu MS, Hsu L, Zhang BH, Shen NP, Lu H, Li SJ (2010) The experiences of cancer-related fatigue among Chinese children with leukaemia: a phenomenological study. Int J Nurs Stud 47(1):49-59

47. Tong A, Sainsbury P, Craig J (2007) Consolidated criteria for reporting qualitative research (COREQ): a 32-item checklist for interviews and focus groups. Int J Qual Health Care J Int Soc Qual Health Care/ISQua 19(6):349-357. doi:10.1093/intqhe/ mzm042

48. Dupuis LL, Milne-Wren C, Cassidy M, Barrera M, Portwine C, Johnston DL, Silva MP, Sibbald C, Leaker M, Routh S, Sung LL (2010) Symptom assessment in children receiving cancer therapy: the parents' perspective. Support Care Cancer 18(3):281-299

49. Fielden AL, Sillence E, Little L (2011) Children's understandings' of obesity, a thematic analysis. Int J Qual Stud Health Well Being 6. doi:10.3402/qhw.v6i3.7170

50. Tomlinson D, von Baeyer CL, Stinson JN, Sung L (2010) A systematic review of faces scales for the self-report of pain intensity in children. Pediatrics 126(5):e1168-e1198. doi:10.1542/peds.20101609 